\title{
Serum Cystatin C as a Predictor of Acute Kidney Transplant Rejection
}

\author{
Fadhil B. Shamkhi* \\ Ala Sh. Ali* \\ Hedef D. El-Yassin**
}

\author{
MSc \\ FIBMS \\ BSc, PhD, MRSC
}

\begin{abstract}
:
J Fac Med Baghdad 2015; Vol.57, No.3 Received Feb. 2015 Accepted Jun.2015

Background: Accurate and rapid assessment of allograft function is essential. Cystatin $\mathrm{C}$ has recently been proposed as an alternative marker of glomerular filtration rate (GFR). Its diagnostic value for the longitudinal assessment of graft function has not been addressed well.

Objective: To study the validity of cystatin $\mathrm{C}$ as an early marker and predictor of acute transplant rejection in the first week post transplantation.

Subjects and Methods: Sixty six renal transplants recipients recruited. The study conducted in four renal transplantation centers in Baghdad for the period from September to December 2011. Serum creatinine and cystatin C concentrations measured 48 hours before transplantation and day 3 and 7 post transplantation.

Results: Serum Cystatin C observed to significantly increased at day $3(p<0.0001)$ and still increased at day 7 in the rejection. On day 3 areas under the receiver operating characteristic (ROC) curves were 0.749 for creatinine and 0.909 for cystatin C.

In patients with acute rejection, serum cystatin $\mathrm{C}$ level elevated earlier than serum creatinine.

Conclusion: Serum cystatin $\mathrm{C}$ seems to be a valuable marker of renal function in the first week post transplantation.

Key words: Cystatin C, Renal Transplantation, Acute Rejection.
\end{abstract}

\section{Introduction:}

Renal transplantation is the best treatment option for ESRD patients. (1) Accurate and rapid assessment of renal function and glomerular filtration rate (GFR) is crucial in renal transplant recipients. (2) Many methods to determine GFR have been described, including clearance assays using the "gold standards." of exogenously administered substances such as inulin. However, they are rarely used for routine measurements due to their complexity. Measuring serum creatinine is the most commonly used method to rapidly assess kidney function, but it also has several disadvantages such as inaccuracies attributable to gender differences, muscle mass changes, or variations in tubular secretion of creatinine. (3) Human cystatin $\mathrm{C}$ is a non glycosylated, low molecular weight (13-kd, 132amino-acid) protein that is produced by all nucleated cells at a constant rate, modulated by intracellular protein, freely filtered by the renal glomeruli, and catabolized in the tubules. Cystatin $\mathrm{C}$ and others has been proposed as a suitable alternative to detect a reduced GFR. $(4,5)$ Its endogenous production rate is unaltered during inflammatory processes. It appears to be independent of gender, age, nutrition, medications, or body mass. Furthermore, its renal clearance is similar to that of exogenous substances. (6) Cystatin $\mathrm{C}$ increases about one to two days earlier than serum creatinine in patients developing

\footnotetext{
*Biochemistry. Nephrology and Renal Transplantation Center, The Medical City, Baghdad, Iraq.

**Dept. of Biochemistry, College of Medicine, Baghdad University. Email: ala1975@gmail.com.
}

AKI. $(7,8)$ Cystatin C based GFR after transplant has been used to detect allograft rejection and monitor drug nephrotoxicity, with reported diagnostic value. In kidney transplant patients, cystatin $\mathrm{C}$ was reported to be more sensitive than serum creatinine for detecting decreases in GFR and delayed graft function, offering an opportunity for timely intervention. (9, 10) Cross-sectional studies in patients with stable transplant function have indicated that serum Cystatin $\mathrm{C}$ discriminates an abnormal GFR more sensitively than serum $\mathrm{Cr}$ in the transplant population. (11) The measured serum cystatin $\mathrm{C}$ values are more stable with less inter individual variations. This is in contrast to the measured values of creatinine. This can be explained by a non return of the filtered cystatin $\mathrm{C}$ to the circulation. Thus, as long as glomerular filtration is preserved, serum cystatin $\mathrm{C}$ remains stable. Creatinine but not cystatin $\mathrm{C}$ is also secreted by the cationic organic acid pathway, a mechanism that displays a large inter-individual variation. $(12,13,14)$ Cystatin $\mathrm{C}$ based GFR calculation has some limitations in situations involving treatment with high doses of steroids and the presence of hypo- or hyperthyroidism. $(1516,17)$ Here we study validate cystatin $\mathrm{C}$ as an early predictor of acute rejection post kidney transplantation in Iraqi renal transplant recipients.

\section{Patients and Method}

This cross sectional study enrolled sixty six renal transplant recipients with a mean age of $36.9 \pm 11.4$ years old and conducted in four renal transplantation centers in Baghdad for the period 
from September 2011 to December 2011. There were two governmental centers (Nephrology and Renal Transplantation Center, the Medical city and Al-Karama Teaching hospital) and two private centers (Al-khayal and Janine private hospitals) in Baghdad.

All patients interviewed, examined and signed an official consent of acceptance to be recruited in the study recorded. All their pre-transplantation clinical and laboratory data reviewed. Any documented evidence of true thyroid disease rendered the patient ineligible for the study.

\section{Blood samples:}

Samples were collected 48 hours pre transplantation, and the 3rd day and in the 7th day post transplant. Five milliliter of blood drawn from each patient after an overnight fasting by venous arm puncture, and was allowed to clot and settle for 1520 minutes at room temperature. Samples were centrifuged at $3000 \mathrm{rpm}$ for 15 minutes. The sera were removed by disposable micropipette then analyzed. Each serum sample was analyzed for cystatin c, urea, creatinine and glucose. All assays were done by running at least duplicates sample for test, control, standard, and the results of these tests were expressed as (mean $\pm \mathrm{SD}$ ). The Cystatin $\mathrm{C}$ assay employed the competitive inhibition enzyme immune assay technique with an antibody specific to cystatin $\mathrm{C}$ has been pro coated onto a microplate. Standards or samples are added to the appropriate microliter plate wells with HRP-conjugated cystatin $\mathrm{C}$ and incubated. The kit provided by Cusabio, China. The normal value range of this kit was up to $60 \mathrm{ng} / \mathrm{ml}$ after control for the local population. $(18,19)$ Serum urea was determined by using a ready-made laboratory kit supplied by Bio Merieux AS, France. The principle of determination was based on the enzymatic hydrolysis of urea. The normal value range for that kit was $20-45 \mathrm{mg} / \mathrm{dl}$. Serum creatinine was determined utilizing a ready-made laboratory kit csupplied by Randox Laboratories, England. It had been determined based on the reaction of creatinine in alkaline solution, with picrate to form a colored complex ( Jaffe reaction). The normal value range for the kit was $0.7-1.4 \mathrm{mg} /$ $\mathrm{dl}$ and $0.7-1.2 \mathrm{mg} / \mathrm{dl}$ for male and female respectively. (19) Glucose level determined by using an enzymatic colorimetric method with a commercially available kit, the fasting plasma glucose (FPG) was determined. It is based on the principle that glucose is oxidized by glucose-oxidase (GOD) to gluconate and hydrogen peroxide. Value more than $126 \mathrm{mg} / \mathrm{dl}$ regarded as hyperglycemia.Four variables MDRD equation used to calculate eGFR for standardized creatinine as eGFR $=175 \times$ standard $\mathrm{SCr}^{-1.154} \times$ age $^{-0.203} \times 1.212$ (if African American) $\times$ 0.742 (if female). (18) CKD-EPI cystatin equation adjusted for age, sex, and race used to calculate eGFR for Cystatin $\mathrm{C}$ as $\mathrm{eGFR}=127.7 \times \mathrm{CysC}^{-1.17} \times \mathrm{age}^{-0.13} \times 0.91$ (if female) $\times 1.06$ (if African American). (18) Acute allograft dysfunction/ rejection proved by histopathology.

\section{Statistical Analysis:}

The results were presented as sample size (n), mean \pm standard deviation (SD), and standard error of mean (SEM). The statistical significance between the groups was analyzed by study -Pearson chi-square test, t-test and correlation test between various parameters considering $\mathrm{P}$-value $<0.05$ as significant, $\mathrm{P}$-value $<0.001$ as highly significant. All statistical significance was done using SPSS version 10.01 computer software (Statistical Packages for Social Sciences).

\section{Results:}

The study recruited sixty six renal transplant recipients with 42 males and 24 females. Their mean age was $36.9 \pm 11.43$ years. The mean body mass index (BMI) was $22.7+2.87 \mathrm{~kg} / \mathrm{m}^{2}$. Hypertension was the prevalent cause of ESRD in the study group (78.8\%) followed by diabetes mellitus (16.7\%), lupus nephritis $(3 \%)$ and recurrent urinary tract infections $(1.5 \%)$ respectively.Fifty eight patients $87.8 \%$ had excellent graft function. The other 8 rejected and rejection confirmed by allograft biopsy. Table 1 describes the Baseline characteristics of the study group.

Table 1: The Baseline characteristics of the study group

\begin{tabular}{ll}
\hline Age yr & $36.91 \pm 11.43$ \\
\hline $\begin{array}{l}\text { Gender } \\
\text { Male } \\
\text { Female }\end{array}$ & $\begin{array}{l}42 / 66(63.3 \%) \\
24 / 66(36.4 \%)\end{array}$ \\
\hline BMI & $22.70 \pm 2.87$ \\
\hline Cause of ESRD & \\
$\quad$ Hypertension & $78.8 \%$ \\
DM & $16.7 \%$ \\
Lupus nephritis & $3 \%$ \\
Repeated UTI & $1.5 \%$ \\
\hline Excellent graft function & $58(87.8 \%)$ \\
\hline Biopsy proven Acute rejection & $\mathbf{8 ( 1 1 . 2 \% )}$ \\
\hline
\end{tabular}

The mean serum cystatin C 48 hours before transplant was higher in the rejected group than recipients with excellent graft function $(1027.37 \pm 457.56 \mathrm{vs} .922 .60 \pm 334.86 \mathrm{ng} / \mathrm{ml})$ but this was not statistically significant difference $(\mathrm{P} 0.001<$ ) by ANOVA test. There was a highly significant difference in serum cystatin $\mathrm{C}$ levels between rejected and successful transplant groups at day $3(\mathrm{P} 0.001<)$. In successful transplants, serum cystatin c level decreased significantly day 7 of transplantation compared with the pre-transplantation values $(p<0.0001)$.In opposite to cystatin $\mathrm{C}$, serum creatinine the rejected group was not significantly elevated at day 3 compared to the pre transplantation values $(2.8 \mathrm{mg} / \mathrm{d}$ vs. $7.6 \mathrm{mg} / \mathrm{dl}$. $(\mathrm{p}>0.05))$. At day 7 the difference was statistically significant (5.1 vs. 7.6 $\mathrm{mg} / \mathrm{dl},(\mathrm{p}<0.001))$ implicating the delayed elevation of serum 
creatinine in response to acute graft injury. Figure 1 shows the difference in cystatin $\mathrm{C}$ values between the two groups. There was significant positive correlation between cystatin-C level at day 3 and day 7 with the FBG level $(\mathrm{p}<0.0001)$. Receiver Operator Curve (ROC) Analysis revealed the association between rejection and serum $\mathrm{CyC}$ in day 3 and day 7 (Cystatin $\mathrm{C}$ day $3=0.909$; Cystatin $\mathrm{C}$ day $7=0.943$ ). When compared to creatinine there was significant positive correlation between cystatin C level at day 3 in rejected recipients (0.909 vs. 0.749). At day 7 the association was not significant. Figure 2 discloses the correlation between cystatin $\mathrm{C}$ and creatinine in patients with rejected graft. Figure 3 shows ROC plots for the diagnostic accuracy of serum concentration of Cystatin $\mathrm{C}$ and Creatinine at day 3. Table 2 shows the frequency distribution of the study group mean serum cystatin $\mathrm{C}$ and creatinine by time before and after transplantation.

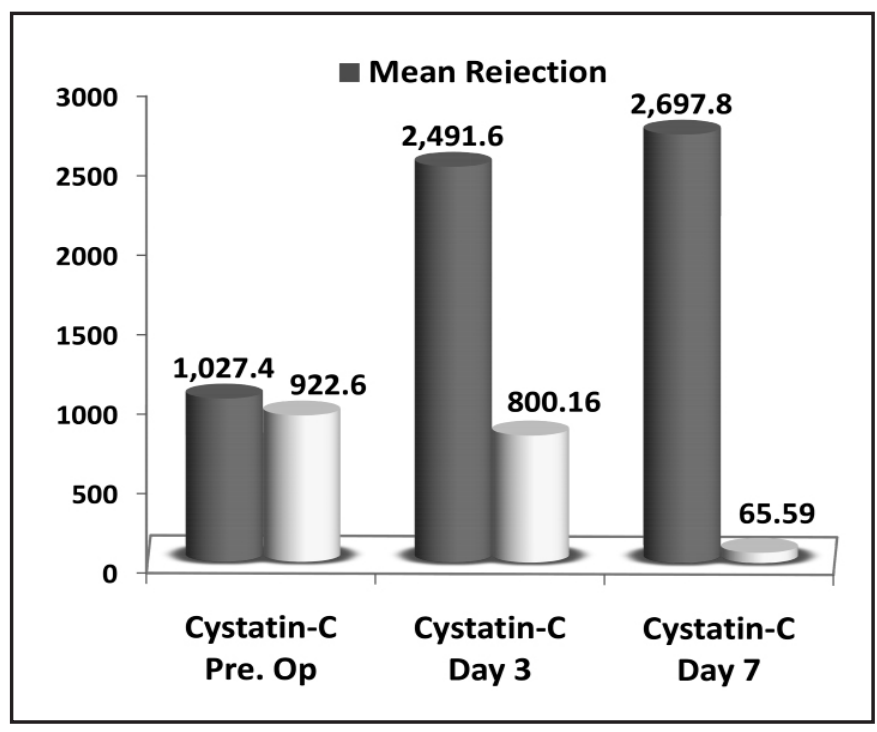

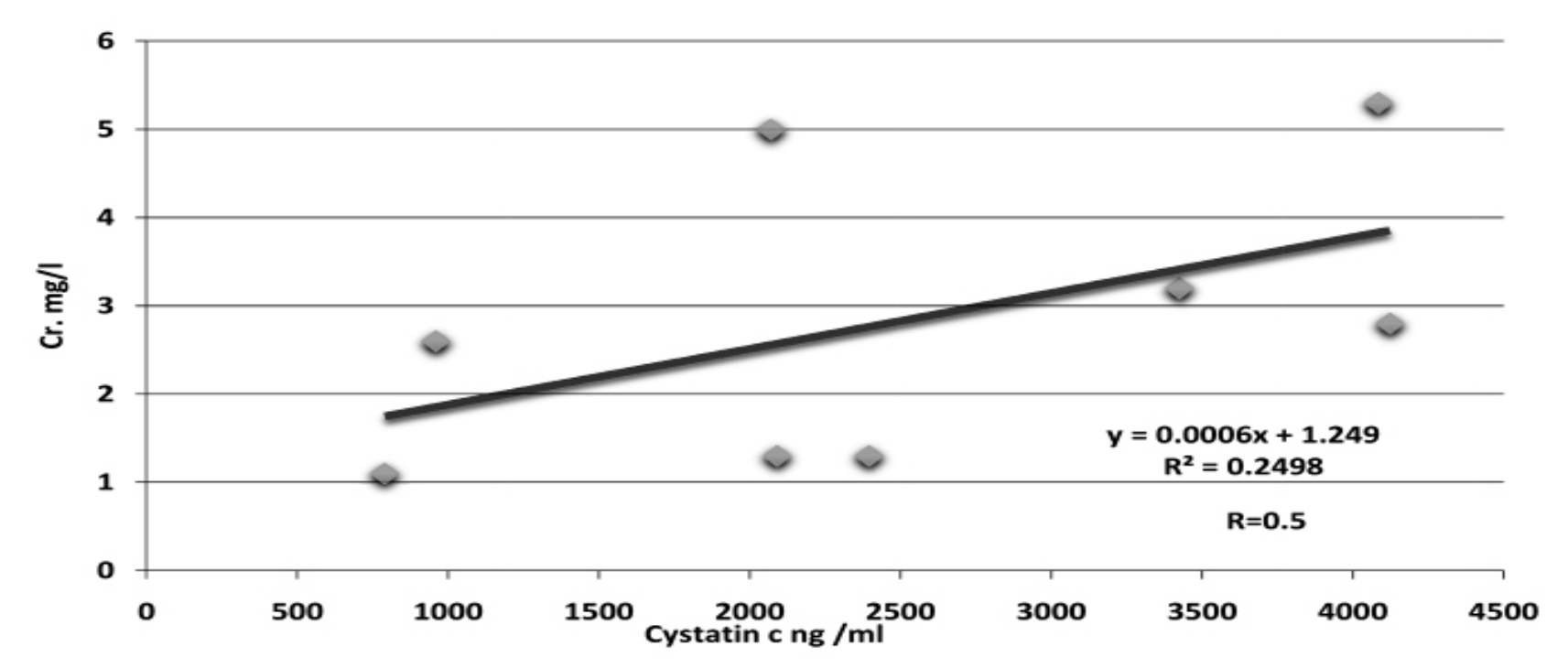

Figure 1 : The frequency of distribution the study group by sCyc in the excellent graft function and the rejected group

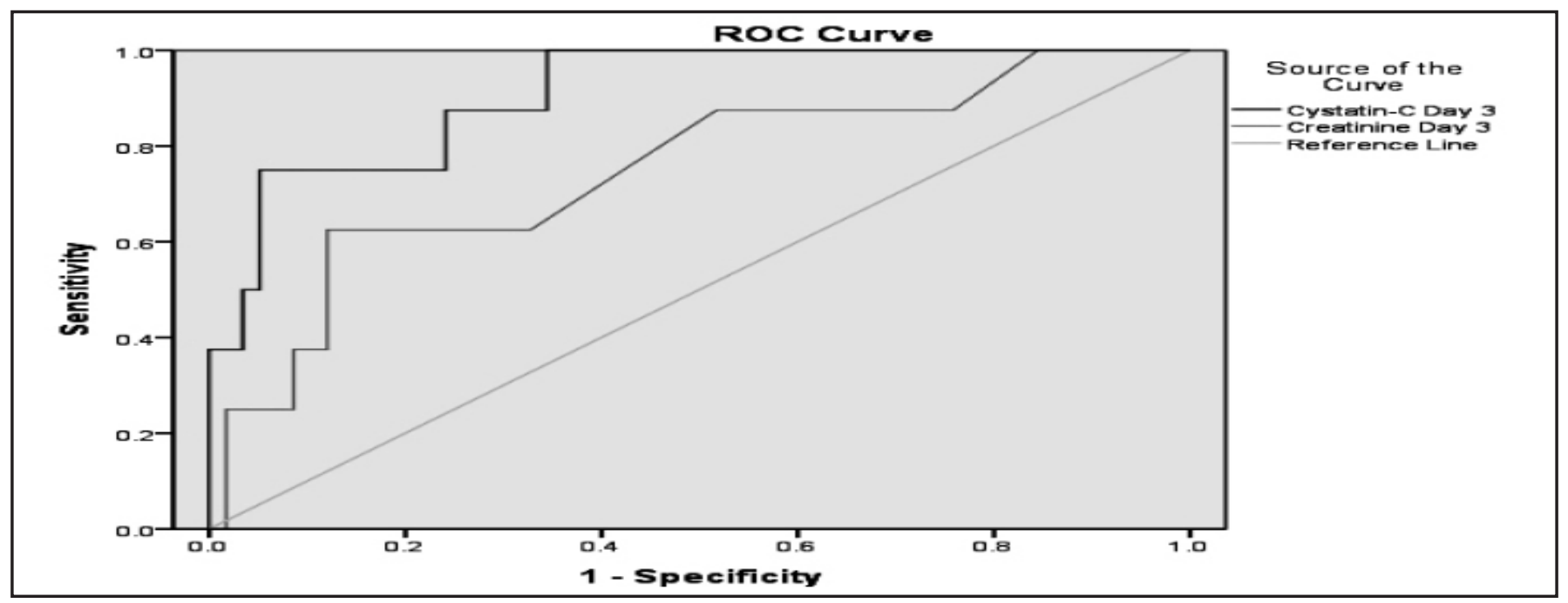

Figure 2: The correlation between cystatin- $\mathrm{C}$ and creatinine in patients with rejected graft 
Table 2: The frequency distribution of the study group mean serum Cyc and creatinine by time before and after transplantation.

\begin{tabular}{ccccccc}
\hline & \multicolumn{2}{c}{ Excellent Graft Function } & \multicolumn{3}{c}{ Rejection } \\
\cline { 2 - 7 } & 48 hr pre Tx & Day 3 & Day 7 & 48 hr pre Tx & Day 3 & Day 7 \\
\hline CyC & 922.6 & 800.16 & 65.5 & 1024.7 & 2491.6 & 2797.8 \\
\hline Cr & 7.36 & 1.62 & 1.24 & 7.45 & 2.83 & 4.36 \\
\hline
\end{tabular}

\section{Discussion:}

In this study serum cystatin $\mathrm{C}$ seems to be a marker of GFR that bears certain advantages over the most widely used surrogate marker of creatinine based GFR. The important one is the early elevation prior to creatinine with a predictive potential on the immediate and possibly the short term course pos transplantation. In kidney transplantation, it is still unclear if cystatin $\mathrm{C}$ offers significant advantages over creatinine (and derived GFR estimates) for long-term management of allograft function. $(20,21)$ Although diabetes mellitus is the most common cause of ESRD worldwide, still the number of transplanted diabetics in our country is not consistent with the international data because of the inherent fear of surgeon to go for diabetis with their multiple comorbidities. Diabetes and pre-diabetes associated with $8.5 \%$ higher levels of cystatin $\mathrm{C}$ and $3.9 \%$ lower levels of creatinine. This can be explained in part by relation to body mass, mostly fat mass; but the mean BMI of the study group was $22.7+2.8$ which is not the definition of obesity. In a study by Lu Wei there was an Influencing coefficients of factors on serum cystatin $\mathrm{C}$ in patients younger and older than 60 years old $(0.075$ and 0.015 respectively). $(22,23)$ In the present study, during the first few days after transplantation the increase in cystatin $C$ serum levels subsequent to high intravenous doses of corticosteroids administered during the first 3 days after transplantation. Other factors may contribute like leakage of cystatin $\mathrm{C}$ from the tubules to the circulation, and impaired filtration of cystatin $\mathrm{C}$ caused by increased protein binding. $(24,25,26)$ The maximum dose of steroids used was $7 \mathrm{mg} / \mathrm{kg} /$ day and the dose variation in the study population was small. This probably renders the steroids effect on cystatin level not so apparent. The use of Calcinurine inhibitors could also explain some observations of cystatin $\mathrm{C}$ concentrations in the transplant population. $\mathrm{Xu}$ et al and Poge et al both found lower cystatin $\mathrm{C}$ concentrations in patients using cyclosporine. However, Bökenkamp et al found no association between cyclosporine dose or cyclosporine trough concentration and cystatin $\mathrm{C}$ level in 44 kidney transplant recipients. Discrepancies in these studies might be caused by lack of adjustment for kidney function by using an accepted reference standard like $99 \mathrm{mTc}-$ DTPA with no association between mycophenolate mofetil, tacrolimus, or cyclosporine use and cystatin C level. $(27,28$,
29, 30) During the first 3 days after transplantation, there was strong correlation between serum cystatin $\mathrm{C}$, creatinine and GFR. Cystatin C level started to elevate on day 3 and continued to rise significantly on the seventh day in rejection patients. From day 3 through day 7 there was a significant positive correlation between serum levels of creatinine and cystatin $\mathrm{C} r=0.5$. Thus Cystatin $\mathrm{C}$ was/ may be more sensitive and specific than creatinine for estimation of GFR with acceptable sensitivity and specificity. Reza Hekmat and Hamid Eshraghi suggested that, in patient with acute rejection in the 7th day after transplantation, the increase in cystatin $\mathrm{C}$ level began approximately 4 days before serum creatinine began to increase. (31) Thus after transplantation, cystatin $\mathrm{C}$ may be a more accurate marker of glomerular filtration rate than plasma creatinine. It may allow earlier diagnosis of renal dysfunction than doe's plasma creatinine but it's still not the sole marker for successful transplantation and graft function assessment needs other markers to be confirmed. This may be of clinical importance, for both the presence and the duration of delayed graft function (DGF), therapeutic interventions and may correlate with both short and long-term allograft survival.

\section{Authors Contribution:}

Fadhil B. Shamkhi: Sample Collections, Lab studies and Patient follow up.

Ala Sh. Ali: Study Design and Manuscript Writing.

Hedef D. El-Yassin: Literature review, laboratory Studies and Lab Supervision.

\section{References:}

1. Gabriel M. Danovitch. Options for patients with End-Stage Renal Disease. In: Gabriel M. Danovitch (Fifth Ed.). Handbook of Kidney Transplantation.LWW. Philadelphia.2010.

2. Li FK, Ho SK, Yip TP, et al: Cystatin $C$ assay for the detection of renal dysfunction in Chinese renal transplant patients. Clin Chim Acta. 2002; 322:133.

3. S.H. Akbas, A. Yavuz, M. Tuncer et al. Serum Cystatin C as an Index of Renal Function in Kidney Transplant Patients. Transplantation Proceedings.2004; 36: 99-101.

4. Hermida J, Romero R, Tutor JC: Relationship between serum cystatin $C$ and creatinine in kidney and liver transplant patients. Clin Chim Acta.2002; 316:165.

5. J.J. Berenguer-Pina, J. Noguera, F. Can izares, et al. Cystatin C: A Marker of Glomerular Filtration Rate in Liver Transplantation. Transplantation Proceedings. 2002; 34, 268-269.

6. Le Bricon T, Thervet E, Benlakehal M, et al: Changes in plasma cystatin $C$ after renal transplantation and acute rejection in adults. Clin Chem.1999; 45:2243.

7. Hase-Fielitz A, Bellomo R, Devarajan P, et al. Novel and conventional serum biomarkers predicting acute kidney injury 
in adult cardiac surgery-a prospective cohort study. Crit Care Med. 2009. E-pub ahead of print. IVSL

8. Herget-Rosenthal S, Marggraf G, Hüsing J, et al. Early detection of acute renal failure by serum cystatin $C$. Kidney Intl. 2004; 66:1115-1122.

9. Pöge U, Gerhardt T, Stoffel-Wagner B, et al. Cystatin $C$-based calculation of glomerular filtration rate in kidney transplant recipients. Kidney Intl. 2006; 70:204-210.

10. Le Bricon T, Thervet E, Benlakeha $M$, et al. Changes in plasma cystatin $C$ after renal transplantation and acute rejection in adults. Clin Chem.1999; 45:2243-2249.

11. T.D. Leach, C. Kitiyakara, C.P. Price, J.M. Stevens, and D.J. Newman. Prognostic Significance of Serum Cystatin C Concentrations in Renal Transplant Recipients: 5-Year Follow-Up. Transplantation Proceedin. 2002; 34, 1152-1158. 12. Perrone RD, Madias NE, Levey AS. Serum creatinine as an index of renal function: new insights into old concepts. Clin Chem.1992; 38:1933.

13. Levey AS, Berg RL, Gassman JJ, et al. Creatinine filtration, secretion and excretion during progressive renal disease. Modification of Diet in Renal Disease (MDRD) Study Group. : Kidney Int. 1989; 27(suppl 1):S73,.

14. A. Mendiluce, J. Bustamante, D. Martin, et al. Cystatin C as a Marker of Renal Function in Kidney Transplant Patients. Transplantation Proceedings.2005; 37, 3844-3847.

15. Pöge U, Gerhardt T, Bökenkamp A, et al. Time course of low molecular weight proteins in the early kidney transplantation period-influence of corticosteroids. Nephrol Dial Transplant. 2004;19: 2858-2863. IVSL

16. Fricker M, Wiesli P, Brändle M, et al. Impact of thyroid dysfunction on serum cystatin C. Kid Intern. 2003; 63: 19441947.

17. Plebani M, Dall'Amico R, Mussap M, et al. Is serum cystatin $C$ a sensitive marker of glomerular filtration rate $(G F R)$ ? A preliminary study on renal transplant patients. Ren Fail. 1998; 20:303 - 9.

18. Hazel Finney,David J Newman,Christopher P Price. Adult reference ranges for serum cystatin $C$, creatinine and predicted creatinine clearance. Ann Clin Biochem 2000; 37:1 49-59.

19. Blirup-Jensen S, Grubb A, Lindstrom V, Schmidt C, Althaus H. Standardization of Cystatin $C$ : development of primary and secondary reference preparations. Scand J Clin Lab Invest Suppl. 2008; 241:67-70.

20. Levey AS, Coresh J, Greene T, et al. Using standardized serum creatinine values in the MDRD Study equation for estimating GFR. Ann Intern Med. 2006; 145: 247-254.

21. G. Filler et al. Cystatin $C$ as a marker of GFR-history, indications, and future research. Clinical Biochemistry. 2005; 38: $1-8$.

22. Lesley A. Stevens, Christopher H. Schmid1, Tom Greene, et al. Factors other than glomerular filtration rate affect serum cystatin C levels. Kidney International (2009) 75, 652-660.
23. Lu Wei, Xiaoshuang Ye, Xiaohua Pei, Jianqing Wu, Weihong Zhao. Reference Intervals for Serum Cystatin C and Factors Influencing Cystatin C Levels Other than Renal Function in the Elderly. 2014. PLoS ONE 9(1): e86066. doi:10.1371/ journal.pone.0086066.

24. Risch L, Herklotz R, Blumberg A, Huber AR. Effects of glucocorticoid immunosuppression on serum cystatin $C$ concentrations in renal transplant patients. ClinChem 2001; 47: 2055-9.

25. Bökenkamp A, van Wijk JA, Lentze MJ, Stoffel-Wagner $B$. "Effect of corticosteroid therapy on serum cystatin $C$ and beta2-microglobulin concentrations”. Clin. Chem. 2002; 48 (7): 1123-6.

26. Geramizadeh B, Azarpira N, Avatollahi M, Rais-Jalali GA, Aghdai M, Yaghoobi $R$ et al. Value of serum cystatin $C$ as a marker of renal function in the early post kidney transplant period. Saudi J Kidney Dis Transpl. 2009; 20(6):1015-7.

27. Xu et al Xu H, Lu Y, Teng D, Wang J, Wang L, Li Y: Assessment of glomerular filtration rate in renal transplant patients using serum cystatin C. Transplant Proc 38:20062008, 2006

28. Poge U, Gerhardt T, Stoffel-Wagner B, et al: Betatrace protein-based equations for calculation of GFR in renal transplant recipients.Am J Transplant 8:608-615, 2008Bökenkamp et al.

29. Bökenkamp A, Domanetzki M, Zinck R, Schumann G, Byrd $D$, Brodehl J: Cystatin C serum concentrations underestimate glomerular filtration rate in renal transplant recipients. Clin Chem 45:1866-1868, 1999

30. Christine A. White, Ayub Akbari, Steve Doucette, et al. Effect of Clinical Variables and Immunosuppression on Serum Cystatin $C$ and Beta-Trace Protein in Kidney Transplant Recipients. AJKD. 2009:54, No 5, 2009: 922-930.

31. Reza Hekmat, Hamid Eshraghi. Comparison of Serum Cystatin $C$ and Creatinine Levels to Evaluate Early Renal Function after Kidney Transplantation. IJMS.2009; Vol 34, No 2 . 